\title{
The Case of Job Satisfaction of Previously Disadvantaged Secondary School Principals
}

\author{
PT Maforah \\ Tshwane University Of Technology, Pretoria, South Africa \\ maforahpt@tut.ac.za
}

\section{Doi:10.5901/mjss.2015.v6n1s1p345}

\begin{abstract}
This study investigates the factors that affect the job satisfaction of principals of previously disadvantaged secondary schools in the North West Province. The aims of the study were to determine-through qualitative means-the factors that influence the job satisfaction of the principals, and thereby make recommendations on ways to improve their job satisfaction. A phenomenological approach was employed to a select eight principals from the sampled schools. The results indicate that the factors that enhanced the job satisfaction of the selected principals related to the nature of their work. Their interpersonal relationships were also gratifying. A majority of the principals were frustrated with poor management on the part of the Department of Basic Education (DBE). This was linked to a lack of autonomy among the principals, excessive bureaucracy, and poor policies. The principals believed that these policies exacerbated the problems they already had of ill-disciplined learners. The DBE can do well to consider the challenges faced by principals in order to address the quality of teaching and learning in public schools, as there is direct correlation between effective leadership and high learner performance.
\end{abstract}

Keywords: Job dissatisfaction; principals; previously disadvantaged secondary schools; theories on job satisfaction; school management

\section{Introduction}

Education is critical in South Africa as an emerging economy and developing country. Hence school principals need to experience job satisfaction in order to be more productive in their jobs. They form an integral part in the functioning of any school. The principal determines the vision and sets the tone for the day to day operations of the school. The South African education system caters for both public and private education systems. The public schools are by law defined as equal and are in principle supposed to be, but are not yet in practice. Public schools are situated in suburban areas, townships and rural areas. Public schools that were previously known as "Model C" schools are historically more resourced than all other public schools. There still exists a vast difference between previously advantaged public schools (model $\mathrm{C}$ type) and previously disadvantaged public schools. Not only is the difference in facilities, but in other cases it involves commitment and discipline (Mtshali, 2002:10).

Adams (1999) indicates that principals might face challenges that may vary in magnitude due to the different circumstances they operate under. The challenges can be things such as, the erosion of authority, lack of support, long working hours and a stressful political environment. The principals in previously disadvantaged schools do however have unique challenges that include factors like, competition with suburban schools for learners, lack of basic infrastructure or maintenance thereof, declined culture of teaching and learning, poor performance, violence and absent educators due to various factors (Lindle, 2004; Newman, 2008; Makwabe, 2009; Govender, 2008).

It is important to state that in spite of the challenges, there is still a very low turnover rate of principals in schools. This is because most principals are at an age where a change in career is not an option. In addition, the principals are faced with limited mobility and they end up staying on, whatever the circumstances they might be faced with. What cannot be ignored is what Pinter (2008:207) refers to as a state of job dissatisfaction that can result due to the challenges that principals face. This is often accompanied by withdrawal symptoms that consist of passive compliance and minimal attempts to perform.

It is however, possible for principals to experience high levels of job satisfaction (Oplatka, 2004:45). This research established the factors that influence the job satisfaction of previously disadvantaged secondary school principals. Very little research has been done within the South African context that focuses on the job satisfaction of school principals (Maforah \& Schulze, 2012:228). It is for this reason that this study adds value to ongoing discourse on job satisfaction of school principals. The main research question was therefore: What influences the job satisfaction of principals of previously disadvantaged secondary schools? The ensuing discussion focuses on previously disadvantaged secondary schools because they experience more challenges due to limited resources that they have to operate under. 


\section{Conceptual and Theoretical Issues}

'Job satisfaction' is a difficult concept to define as there is no universally agreed upon definition of the term. A range of definitions only manage to give descriptions of the possible consequences of job satisfaction (Evans, 1997b:321). 'Job satisfaction' is viewed by researchers as a multi-dimensional concept that includes a person's general attitude towards his/her work (Steyn \& Van Wyk, 1999:37). A closer investigation at the concept of job satisfaction refers to a person's feeling about his/her job, or the degree to which an individual enjoys his/her work (Mimon \& Oplatka, 2008:137). Mercer (1997:57) defines 'job satisfaction' as the effective reaction of an individual to his or her work. Evans (1997a:833) defines it as "... a state of mind determined by the extent to which the individual perceives his/her job-related needs to being met". This is what makes a job satisfying action difficult to define because it involves an individual's reactions and perceptions. Perceptions and reactions are influenced by several factors and it is possible to obtain different reactions to the same stimulus or situation. For the sake of this article, job satisfaction is defined as a sense of fulfilment brought about by a feeling of achievement and recognition.

Respect, recognition and reward are regarded as critical factors in effective work relationships (Graham \& Messner, 1998:196). The same applies to the work of school principals because they play a central and paramount role in the successful functioning of schools and education in general. The job satisfaction of school principals is central to their effectiveness, seeing that a lot is expected from them. Conley, Glassman and Shaw (2007:55) assert that there is a direct correlation between effective leadership and high learner performance. According to Conley et. al. (2007:55), while high job satisfaction is linked to effectiveness, low job satisfaction can result in at least two dimensions being negatively affected, namely, psychological and physical withdrawal from the job. Disillusioned principals are more likely to give up their jobs. This quitting may not only be physical, but also mental, wherein a person is "physically present and available but is psychologically not there and does not want to be there."

Given this conceptual context, job satisfaction has been a subject of interest and research for some time. Many theories and models have been proposed to depict the issue of job satisfaction, as well as factors that affect it (Mimon \& Oplatka, 2008:135). Fincham and Rhodes (in: Balgobind, 2002:41) write that there are two broad categories of job satisfaction theories, namely content (needs) theories and process theories. The former theory underpins this study. Content theories deal with the fact that employees have needs that are a driving force in how they behave as posited by Maslow, Alderfer, Murray and McClelland (Steers, 1979; Bennett, 1998; Roos 2005:24; Pinder 2008; Jordan \& Jordan 1989).

Of the major theories in the area of job satisfaction, Herzberg's two-factor theory is regarded as the pioneer theory of motivation (Mimon \& Oplatka, 2008:137). Frederick Herzberg undertook a study of those elements in the workplace that produce worker satisfaction or dissatisfaction (Rosenbaum, 1982:21). Unlike Maslow, Murray and McClelland, who did not address the problem of the workplace, Herzberg specifically investigated the role of motivation in the workplace (Steers, 1979:392). His initial research was done with a group of accountants and engineers, but was later extended to various other groups, like housewives, unskilled catering staff, professional women, scientists, teachers, and nurses, from different countries (Mumford, 1972:66). Herzberg (1976:60) says that "it is what man can accomplish that makes him human, and what he can accomplish on the job will determine his human feelings". Herzberg posits that the factors involved in producing job satisfaction are not the same as the factors that lead to job dissatisfaction. These factors are also not the opposite of each other. The feelings of job satisfaction and job dissatisfaction are independent of each other. It is possible for an employee to be happy about certain aspects of the job while unhappy with other aspects (Herzberg, 1976:58; Pinder, 2008:32).

According to Pinter (2008:209), Herzberg's theory argues that jobs must feature a number of characteristics to permit them to arouse and satisfy growth needs. Jobs should permit achievement as well as recognition of the achievement. They should be interesting to perform and should permit feelings of growth, advancement, meaningfulness as well as feelings of responsibility and feedback on the part of the employee. Meaningfulness means that an employee, for example the school principal, has the notion that his/her efforts or input counts for something. Autonomy on the other hand is required for principals to experience a sense of responsibility. Autonomy is the degree to which the job provides substantial freedom, independence and discretion in scheduling work and determining procedures set in carrying it out. According to Mumford (1972:157), autonomy implies control and choice from a number of alternatives. It means setting goals and targets that are both clear and difficult. Job satisfaction can be obtained from setting and attaining targets, particularly if they are self- imposed.

By means of feedback, an individual can obtain knowledge of the actual results of his/her work. Feedback can be two fold, emanating either from the job itself or from the circuit manager or supervisor (Pinder 2008: 211). Feedback from the job is immediate and more satisfying if an individual observes the effect of the results of the task and the reaction of 
the people that one interacts with. For the principal, feedback from the supervisor comes in the form of accountability. Feedback has the strongest correlation with job satisfaction when compared with other characteristics of the work (Whitaker 2003:162).

Recognition is one of the factors regarded as a motivator which is intrinsic to the job. Expecting recognition is a unique human characteristic that is related to growth, and results in job satisfaction (Steyn and Van Wyk 1999:32). Studies in (Graham \& Messner 1998:197) on the job satisfaction of school principals, indicate that intrinsic factors contribute towards job satisfaction. Their research confirmed Herzberg's claims that recognition and self- actualisation were among the major factors that motivated principals to perform at their maximum level and thus led to high degrees of job satisfaction. Ashford(in: Pinder 2008:173) reported on a study where it was found that regardless of a person's seniority, recognition by a more senior person (e.g. the DBE) was seen as more important than recognition from peers or from self-evaluation.

According to the definition of job satisfaction used in this study, recognition brings about a sense of fulfilment that one can describe as self- actualisation. Self - actualisation is the driving force that propels individuals to perform much more than they are currently doing. The bar is raised every time there is recognition after an achievement. This is an important ingredient for school principals (Pinder 2008:73).

\section{Research Method and Data Collection Procedures}

A phenomenological approach that used selected principals of previously disadvantaged secondary schools in the NorthWest province was employed. The province was purposefully selected due to its convenient location and accessibility (McMillan \& Schumacher, 2010:137). Eight participants were purposefully selected for maximum variation. Two female principals and six male principals were used for the sample (this was in proportion of gender in schools, as there are more male secondary school principals than are females). The selection also ensured that the participants had varying years of experience and education, and others taught in rural schools while others in township schools. Semi-structured interviews were conducted. The questions were related to the factors that could influence the job satisfaction of the principals in some way. For example, principals were asked their views on recognition, the kind of feedback they get on their work, the factors that they perceived as satisfactory or non-satisfactory in their daily lives as principals.

To ensure reliability, the data was collected over eight weeks. Interviews were conducted in the most natural settings and all conversations were recorded and later transcribed verbatim. The quoted statements also indicate whether they were made by a male $(M)$ or female $(F)$. Due to ethical considerations, informed consent was obtained from the DBE as well as the participants. Anonymity and confidentiality were guaranteed. Permission to record the interviews was also obtained from the participants.

\section{Critical Empirical Issues Emerging from the Study}

Principals expressed both satisfaction and dissatisfaction with their role and position as school managers. Job-satisfiers included the performance and progress of learners; the enjoyment from working with people who respect them, and make them feel good about themselves; and opportunities for development and self-actualisation. Most of the factors that resulted in dissatisfaction were related to the Department of Basic Education in some way; the people they had to deal with on a daily basis; and the lack of training to be a principal.

\subsection{Job satisfiers}

Most of the respondents indicated that working with learners gave them the most satisfaction. "The fact that I am dealing with young minds, guiding them and advancing them gives me such great pleasure." Male (M)

\section{"Developing the precious minds of African learners ignites a determination and passion for my work." Female (F)}

Good working relationships were highlighted by most principals as a source of satisfaction. Principals value cooperation by staff members, and the School Governing Body (SGB) as a factor that promotes the good running of a school and brings about job satisfaction.

"The working relationship I have with educators and the SGB gives me joy." $(F)$

"A sense of ownership of functions of the school by the staff, Learner Representative Committee (LRC) and the School 
Governing Body (SGB) just makes me happy."(M)

Six of the respondents mentioned the support they receive from their supervisors as a factor that facilitated their job satisfaction.

"The support I get from my circuit manager is good."

Principals included general administrative duties like developing policies, handling finances and project management as satisfiers.

\subsection{Job dis-satisfiers}

Frustration by the Department of Education

The issue mentioned by most principals as a great source of their frustration was with the Department of Basic Education (DBE).

'Working with the Department gives me much grief." (M)

The level of frustration seems to be the same for both male and female principals. What was at the core of the frustration was the level of interference and interruptions from the Department officials in their daily work.

"The authorities come abruptly to the school and disturb one from one's daily plans. I am always out of school, in meetings and I am supposed to be teaching." (F)

"These workshops arranged during school hours by officials from the Department make me want to scream." (M)

To the above, the respondents added their frustration with the lack of support from their supervisors, especially where it concerned dealing with disciplinary issues involving educators.

\subsection{Frustration with Departmental policies}

The respondents mentioned several frustrations concerning Departmental policies. They felt like some of the policies have disadvantaged the schools they were meant to assist. The respondents felt that there was red-tape emanating from the Department, their policies and extreme control. The level of interference and interruptions in the daily working lives by the Department of Basic Education was at the core of the frustration to the majority of principals. Principals felt that this, not only wasted their precious time, but left them feeling like they have no autonomy. They felt like they were not being given ample space to perform their duties to the best of their abilities, for example, "Interference from the circuit office by officials with policy matters at the expense of creativity is my main gripe." One of the examples given by principals is what they referred to as an unwritten policy by the Department of Basis Education that principals needed to ensure that extra classes were conducted on weekends and school holidays. Most principals felt as if they were compelled to have those extra classes and saw that as interference. At the time of the study, most principals believed that decisions about their institutions were taken on their behalf, and they were merely instructed to implement them. This resulted in bitterness and dragging of feet, because some of the decisions taken did not necessarily address the issues the principals were faced with and if given a chance, they would have addressed some of the issues in a different way. One respondent said: "Give the principals the opportunity to act as the school's CEO." (M)

One other policy mentioned by most principals as a source of great frustration is the Section 21 policy. This policy has resulted in most schools that have been classified as serving the poor being made into non-fee paying schools. Most principals felt that while the policy was meant to assist poor communities, in most cases, it left the school poorer. Parents become unwilling to do anything to assist the school, due to the belief that the government should provide for everything. In cases where parents used to partly assist in the upkeep of the school, that stops immediately the school is classified as a Section 21. One respondent said: "The Fact that my school is a non-fee school means that I cannot do certain projects because the regulation is that Section 21 money cannot be used for infrastructure development."(F) Parents do not want to understand this and think that the school has enough money from the government to cater for everything: "Some parents even expect the school to pay for the matric dance." (F) What the parents do not realise is that: "The money is never enough to bring the changes that are required. Our schools remain disadvantaged. I do not see how we are ever going to reach the status of town schools. We are way off." (M)

Principals also expressed concern with the classification process and the fact that once a school has been classified it becomes virtually impossible to return the school to its original classification. What compounded the problem even much further was the amount of time schools have to wait for their allocation of funds from the Department of Basic Education. They spend most of the time without any money in their accounts while waiting for allocations from the DBE, 
with the parents not willing to assist in any way, and yet principals are expected to operate effective schools. The other policy mentioned by several principals is the Post Provisioning Model (PPM) that the DBE uses to allocate teachers to schools. Regarding this policy, one respondent said: "There are insufficient educators in schools due to the allocation policy of the department."(F)

\section{Empirical Analysis and Inferences}

The results of the study showed that most principals of the previously disadvantaged secondary schools are unhappy with the Post Provisioning Model. Principals felt that although the policy is meant to address the Learner- Educator ratio, it does not take into consideration the individual needs the schools might have, concerning issues like the diversity in learning areas and the number of grades that a school might have. This results in some cases with one teacher having to teach a number of learning areas (in some instances without the necessary expertise and experience) or resulting in multi-grades in one class. This obviously affects the quality of teaching and learning. The principal of one such school indicated how in his school, there never was a time when an educator could have a free period, and that included him as the principal. That meant he could not attend to administrative duties that required his time, as that would be at the expense of the learners. He did not have time for class visits and parents had to wait a long time to see him when in class. Most principals felt that the Department would do well to revisit this model.

What seemed to emerge from most respondents is the dissatisfaction over the perceived "obsession" with the grade 12 results that all stakeholders have. Secondary school's day to day activities revolved around making sure that grade 12 results were good at the end of the year. If the grade 12 learners did not perform well, the school was regarded as "trapped", and that meant that the specific school needed special attention from the Department of Basic Education. This results in punitive measures such as unannounced visits by the Department officials, endless meetings and calls for improvement plans.

What is interesting is that some school principals who are heading schools that are regarded as "performing schools" or top schools were also not happy with the kind of treatment they receive from the Department officials. One such principal indicated how discouraging it was to be a principal. He indicated that he tried his best to maintain good standards in spite of the challenges that his school faced, yet he had never over the years received any recognition for the work he does. He said: "As an individual I have not received any recognition for the work and the leadership I am offering my school to remain up there. I have not received a certificate, a trophy, a cheque or a gift voucher. I feel bad because it is like the Department does not recognize what I do as a principal."

Other dissatisfying factors included the physical working conditions that principals have to function under. The lack or inadequate maintenance of infrastructure like classrooms, grounds, water, electricity and roads continue to be a high source of dis-satisfaction for most principals. These basic essentials are what Maslow referred to as lower order needs and Herzberg refers to them as Hygiene factors. Failure to satisfy the lower order needs result in increased job Dissatisfaction.

\section{Conclusion and Implications}

Results from this study of selected previously disadvantaged secondary schools in the North West Province show that there are certain factors that enhance the job satisfaction of the principals and those factors that result in their dissatisfaction. Underpinning this research is the Two Factor Theory by Herzberg. The theory deals with the fact that employees have needs that are a driving force in how they behave. Principals in this study valued feedback and recognition as factors that increase their level of job satisfaction. Two other factors that can be deduced from the results that enhance job satisfaction of the principals are the nature of the work, and interpersonal relationships. It is evident from the results that principals regard their work as stimulating and important. Their work leaves them with a feeling of accomplishment, growth and self-esteem. The satisfaction with the work that the principals have is more evident when the principals have good working relationships with their colleagues, learners, parents and supervisors. These factors are higher-order needs which are intrinsic to the job and serve as motivators as explained by Herzberg.

Although the principals were satisfied with the nature of their work, half of the respondents have, during interviews, indicated that they were dissatisfied with their jobs as principals due to organisational structural issues and would consider leaving the job if the opportunity arose. The results show that the majority of the principals were frustrated with what they regarded as poor management on the part of the Department of Education. The factors raised were the perceived lack of autonomy, the department's policies on Post Provisioning, Section 21, labour Laws on disciplining educators and policies on disciplining learners. The respondents indicated that the factors raised above were enough to 
make them leave their professions if they had a choice. The remaining $50 \%$ expressed the same concern but indicated a willingness to 'stick it out' in their positions as principals. This is a worrying factor if half of the workforce is 'hanging in there' for lack of better choice. This will have a ripple effect on the performance of the educators and the learners.

This research was conducted on a few schools in the North West Province which is predominantly rural and poor. The results in other provinces like Gauteng could have been different due to the different socio-economic factors. This needs further research.

What is of essence in this research is the role that school managers in the form of the supervisors can play to enhance job satisfaction of principals. Supervisors can reduce bureaucracy, implement participatory decision making, recognise effort and performance, use motivational strategies and train all stakeholders. The DBE can do well by reviewing some of its policies after researching on their effectiveness to date and finding out what can be done to enhance performance. More research can therefore be conducted on the impact that some of the departmental policies have on performance, e.g. Section 21 and the Post Provisioning Model (PPM). Job satisfaction of school principals remain pivotal to the effective functioning of schools and cannot as such be ignored.

\section{References}

Adams, J.P. (1999). Good principals, good schools. Education Leadership, 29(1), 1-4.

Balgobind, V. (2002). The impact of transformational leadership on subordinate job satisfaction. Unpublished MAdmin dissertation. Pretoria: University of South Africa.

Bennet, J.A. (1998). The relationship between burnout and job satisfaction amongst fire fighters Conley, S., Glassman, N., \& Shaw, S. (2007). Correlates of job and growth satisfaction among secondary school administrators. Journal of School Leadership, 17(1), $55-85$.

Evans, L. (1997a). Understanding teacher morale and job satisfaction. Teaching and Teacher Education, 13(8), 831-845.

Evans, L. (1997b). Addressing problems of conceptualization and construct validity in researching teachers' job satisfaction. Educational Research, 39(3), 319-329.

Graham, W.M., \& Messner P.E. (1998). Principals and job satisfaction. International Journal of Educational Management, 12(5), 196202.

Govender, P. (2008). Sunday Times, March 10.

Herzberg, F. (1976). Managerial choice: to be efficient and to be human. Homewood: Dow Jones-Irwin.

Jordaan, W., \& Jordaan, J. (1989). Man in context.(2nd ed.). Isando: Lexicon Publishers.

Lindle, J.C. (2004). Trauma and stress in the principal's office: systematic inquiry as coping.

Journal of School Leadership, 14(7), 378- 405.

Maforah, T.P., \& Schulze, S. (2012). The job satisfaction of principals of previously disadvantaged schools: new light to an old issue. South African Journal of Education, 32(3), 227-239.

Makwabe, B. (2009). Sunday Times, May 17.

McMillan, J.H., \& Schumacher, S. (2010). Research in Education: Evidence-based inquiry. (7th ed.). Boston: Pearson.

Mercer, D. (1997). Job satisfaction and the secondary head teacher: the creation of a model of job satisfaction. School Leadership and Management, 17(1), 57-67.

Mimon, R., \& Oplatka, I. (2008). Women principals' conceptions of job satisfaction and dissatisfaction: an alternative view. Leadership in Education, 11(2), 135- 153.

Mtshali, T. (2002). Sunday Times insight, November 10.

Mumford, E. (1972). Job Satisfaction: A study of computer specialist. London: Longman Group Ltd.

Newman, L. (2008). Department of Education. Education Statistics in South Africa at a glance in 2002-2008. Pretoria: Department of Education, 4.

Oplatka, I. (2004). The principal's career stage: an absent element in leadership perspectives. Leadership in organisational behaviour. $\left(2^{\text {nd }}\right.$ ed.). New York: Psychology Press.

Pinder, C.C. (2008). Work motivation in organizational behaviour. (2nd ed.). New York: Psychology Press.

Roos, W. (2005). The relationship between employee motivation, job satisfaction and corporate culture. Unpublished MSc dissertation. Pretoria: University of South Africa.

Rosenbaum, B.L. (1982). How to motivate today's workers. New York: McGraw-Hill, Inc.

Steers, R.M. (1979). Motivation and work behaviour. (2nd ed.). New York: McGraw-Hill Inc.

Steyn, G.M., \& Van Wyk, J.N. (1999). Job satisfaction: perceptions of the principals and teachers in urban black schools in South Africa. South African Journal of Education, 19(1), 37-43.

Whitaker, K.S. (2003). Superintendent perceptions of quantity and quality of principal candidates. Journal of School Leadership, 13(3), 159-179. 